\title{
Correction to: Measurements and Distribution of Atmospheric Particulate-Bound Mercury: A Review
}

\author{
Hui Zhang ${ }^{1}(1) \cdot$ Xuewu $\mathrm{Fu}^{1,2} \cdot$ Xun Wang $^{1,4} \cdot$ Xinbin Feng $^{1,2,3}$
}

Published online: 5 July 2019

๑) Springer Science+Business Media, LLC, part of Springer Nature 2019

\section{Correction to: \\ Bulletin of Environmental Contamination and Toxicology https://doi.org/10.1007/s00128-019-02663-5}

The original version of this article unfortunately contained a mistake in units.

In section Global and Regional Distribution of PBM the unit $\mathrm{pg} \mathrm{m}^{-3}$ was incorrectly written as $\mathrm{ng} \mathrm{m}^{-3}$ in three occurrences. The revised sentence with correct unit of measurement is given below.

Mean PBM concentrations at urban sites ranged from 2.3 to $1180 \mathrm{pg} \mathrm{m}^{-3}$ (mean $225 \pm 174.5 \mathrm{pg} \mathrm{m}^{-3}$ ), significantly higher than the PBM concentrations measured at remote sites (mean $25.3 \pm 29.7 \mathrm{pg} \mathrm{m}^{-3}$ ).
Publisher's Note Springer Nature remains neutral with regard to jurisdictional claims in published maps and institutional affiliations.

The original article can be found online at https://doi.org/10.1007/ s00128-019-02663-5.

Hui Zhang

zhanghui1@mail.gyig.ac.cn

1 State Key Laboratory of Environmental Geochemistry, Institute of Geochemistry, Chinese Academy of Sciences, Guiyang 550002, China

2 CAS Center for Excellence in Quaternary Science and Global Change, Xi' an 710061, China

3 University of Chinese Academy of Sciences, Beijing 100049, China

4 College of Resources and Environment, Southwest University, Chongqing 400715, China 